\title{
Enunciación
}

http://revistas.udistrital.edu.co/ojs/index.php/enunc

DOI: http://dx.doi.org/10.14483/udistrital.jour.enunc.2015.2.a06

\section{Uso de imágenes en clases de Ciencias Sociales y Ciencias Naturales: enseñando a través del potencial semiótico visual ${ }^{1}$}

\author{
Use of images in Social Studies and Science lessons: Teaching through \\ visual semiotic potential
}

\author{
Dominique Taryn Manghi Haquin², Valentina Haas Prieto ${ }^{3}$
}

Para citar este artículo: Manghi, D. y Haas, V. (2015). Uso de imágenes en clases de Ciencias Sociales y Ciencias Naturales: enseñando a través del potencial semiótico visual. Enunciación, 20(2), pp. 248-260.

Recibido: 30-septiembre-2015 / Aprobado: 30-noviembre-2015

\section{Resumen}

Los aprendices acceden al currículo escolar a partir de significados construidos en una variedad de modos semióticos (esquemas, fotos, dibujos, escritura, entre otros); este aprendizaje les permite incorporarse a una visión de mundo propia de una disciplina. Desde una mirada pedagógica y semiótica sobre la interacción en el aula, se focaliza el uso de las imágenes en la enseñanza, en relación con su potencial para crear significado en el aula escolar, en clases de Ciencias Sociales y Ciencias Naturales. Este artículo sistematiza herramientas metodológicas de la semiótica social y la multimodalidad para explorar el potencial semiótico de un conjunto de imágenes usadas por profesores de educación básica y media en una escuela pública. A partir de un corpus audiovisual, tomado de una unidad didáctica completa de Ciencias Sociales y otra de Ciencias Naturales de $3^{\circ}$, $6^{\circ}$ básico y $1^{\circ}$ de educación media, se lleva a cabo un análisis multimodal del discurso. Con los conceptos de metafunción ideacional e interpersonal y las categorías de la gramática del diseño visual se presentan ejemplos de análisis situado de imágenes.
Los resultados dan cuenta de cómo las imágenes ofrecen un potencial de significado que es modificado cuando son usadas por los profesores en el aula. Este análisis puede ser un aporte a los profesores en función de la selección de imágenes y su uso en la mediación cara a cara o los materiales de enseñanza preparados para los aprendices.

Palabras clave: aprendizaje visual, enseñanza multimedia, material audiovisual, material visual, alfabetizador, práctica pedagógica.

\begin{abstract}
Learners access the school curriculum through meanings created among a variety of semiotic modes (diagrams, photographs, drawings, writing, etc.), this learning enables them to join a worldview as they do in each curricular discipline. From a pedagogical and semiotic gaze to classroom interaction, we focus on the use of images in teaching, in relation to their potential to create meaning in social studies and science lessons. This article is part of Fondecyt
\end{abstract}

Investigación enmarcada en proyecto Fondecyt 1130684.

2 Doctora en Lingüística de la Pontificia Universidad Católica de Valparaiso. Profesora Adjunta Escuela de Pedagogía. Pontificia Universidad Católica de Valparaíso, investigadora responsable Fondecyt 1130684. Correo electrónico: dominique.manghi@pucv.cl

3 Doctora en Educación de la Universidad Aconcagua. Coordinadora de prácticas de Educación Básica. Escuela de Pedagogía, coinvestigadora Fondecyt 1130864. Pontificia Universidad Católica de Valparaíso. Correo electrónico: Valentina.haas@pucv.cl 
1130684 and systematizes methodological tools from Social Semiotics and multimodality used to explore the semiotic potential of a set images used by teachers of elementary and secondary in a public school. From an audiovisual corpus of lessons of a complete curricular unit, we analyze Social Studies and Science videos from the two subjects in 3rd, 6th grade of elementary and 1st grade of secondary school. Through a Multimodal Discourse Analysis using the concepts of ideational or representational metafunction and the categories of Visual Grammar

\section{INTRODUCCIÓN}

La mirada multimodal sobre la comunicación constituye un desafío para los investigadores del campo del análisis del discurso en contextos educativos, pues permite ampliar la comprensión de los fenómenos de representación y de comunicación en el aula. La multimodalidad reconoce y valora la variedad de modos semióticos para significar que se utilizan con fines de enseñanza, que superan la lengua oral o escrita (Kress y Van Leeuwen, 2001; Dussel, 2011; Manghi, 2011) incluyendo los dibujos, esquemas, mapas, entre otros, también presentes en la dinámica escolar.

En la actualidad, los potenciales semióticos para representar y comunicar la información computacional, la de los textos escolares y de otros materiales para la enseñanza están asociados inevitablemente al avance de las tecnologías, lo que posibilita incorporar cada vez más recursos semióticos para el diseño de la enseñanza de los contenidos del currículo (Martins, 2006). Este fenómeno repercute en las posibilidades de utilización de las imágenes en el contexto del aula, las cuales cotidianamente son seleccionadas por los profesores para que los estudiantes aprendan a partir de ellas. Es un cambio en las prácticas de aprendizaje y de enseñanza, prácticas semióticas del ámbito escolar, lo que nos obliga a mirar con más detenimiento las posibilidades de crear significado de manera intencionada por parte de los profesores en
Design, we show examples of situated images anylisis. The results show how the meaning in the image is modified when teachers use them in face to face interaction. This analysis should help teachers to select and deploy images in terms of improving the learning process and teaching materials they prepare for students.

Keywords: visual learning, multimedia teaching, audiovisual material, visual material, literacy, teaching practice

la mediación pedagógica. En tal sentido, los docentes en el contexto educativo desempeñan un rol crucial con su mediación, ya que el desafío es generar oportunidades para comprender textos multimodales críticamente (Farías y Araya, 2014) más allá del consumo pasivo en el aula, y avanzar hacia la formación de aprendices que sepan diseñar, producir y distribuir textos multimodales (Kress y Van Leeuwen, 2001) para participar de manera activa y propositiva en la vida ciudadana (Manghi, Badillo y Villacura 2014).

Estudios recientes en contextos latinoamericanos como los de Oteiza (2009), Pereira y González (2011), Llanos y Otero (2012), Altamirano, Godoy, Manghi y Soto (2014), Farías y Araya (2014), entre otros, han revisado el papel de las imágenes en los textos escolares. Estas investigaciones se centran en el análisis de las imágenes y los significados que aportan en sí mismas, o en relación con el texto escrito que las acompaña. A diferencia de estos estudios, el presente trabajo -parte del Fondecyt 1130684- tiene un enfoque situado en la semiosis, y busca contrastar el potencial de significado general de las imágenes que usan los profesores en el aula y cómo este significado cambia cuando es mediado por el profesor.

Este artículo muestra la sistematización de un procedimiento para el análisis multimodal de las imágenes empleadas en el aula escolar en las áreas de Ciencias Sociales y Ciencias Naturales en un estudio de caso en una escuela pública chilena. 
La propuesta metodológica busca aportar a la comprensión del uso de las imágenes para la enseñanza, para avanzar en la definición de la alfabetización semiótica o multimodal así como de la mediación de los profesores en el aula.

A continuación, se presentan los conceptos centrales de la semiótica social y la perspectiva multimodal en la definición de los materiales visuales para la enseñanza como textos multimodales y su importancia en la mediación semiótica. A través de una imagen por curso, los ejemplos seleccionados intentan dar cuenta del potencial semiótico y, por tanto, del potencial para el aprendizaje a partir de imágenes estáticas y dinámicas, las cuales son mediadas por el profesor en la interacción cara a cara.

\section{CONSTRUCCIÓN DE SIGNIFICADOS EN EL AULA Y ALFABETIZACIÓN SEMIÓTICA}

La semiótica social plantea que tanto los significados como los recursos utilizados para significar responden a las necesidades de representación y comunicación de las comunidades que los utilizan (Halliday, 1982); es decir, están asociados a sus prácticas sociales (Van Leeuwen, 2005). De esta manera, los significados que se construyen en una comunidad, en particular el aula escolar de Ciencias Naturales y en la de Ciencias Sociales, lejos de corresponder a representaciones semióticas de conceptos dispuestos en la realidad, responden más bien a las necesidades de cada comunidad de plantear una interpretación de la experiencia humana (Halliday y Martin, 1997).

Cada disciplina ha plasmado en el tiempo su cúmulo de conocimientos en diversos artefactos semióticos, entre ellos: mapas, fotos, esquemas o fórmulas, textos con código escrito e imagen, entre otros (Kress y Van Leeuwen, 2001). En el caso del discurso de las Ciencias Naturales, este se encuentra entre aquellos que se consideran como construcciones multimodales (Lemke, 1998), al igual que la geografía, dada su naturaleza visual (Van Leeuwen y Humphrey, 1996) y la historia, a través de su trabajo con fuentes primarias y secundarias muchas de ellas visuales (Manghi, Badillo y Villacura, 2014). Esto significa que los miembros de cada una de estas comunidades construyen su discurso a través de elecciones entre diversos sistemas funcionales de signos disponibles en su entorno cultural, y no exclusivamente el lingüístico.

La idea de los signos con una función social ha sido desarrollada por la teoría semiótica sistémica funcional que reconoce tres significados o metafunciones simultáneas cada vez que se crea significado: ideacional, interpersonal y textual (Halliday, 1982). Esto implica que cada vez que nos comunicamos, nuestros textos transmiten tres tipos de significado: 1) ideacional: representamos la experiencia; 2) interpersonal: establecemos relaciones con otros en un intercambio comunicativo, y 3) textual: entretejemos los distintos recursos o modos semióticos disponibles para la representación y la comunicación para darle unidad o cohesión a nuestros significados. De esta manera, la semiosis incluye la idea de la función representativa tradicional en semiótica y lingüística, pero además el aspecto personal e interpersonal, respecto del posicionamiento de quien crea significado en cuanto al contenido de su expresión, así como de sí mismo y su interlocutor, considerando que los significados no son neutros.

De acuerdo con esta teoría, los significados siempre se dan en un contexto, relacionando al texto con dos niveles de contexto: el de situación y el de cultura. Las opciones que nos ofrecen los sistemas semióticos para construir los significados textuales responden y, al mismo tiempo, construyen las condiciones del contexto de situación, las que a su vez se entienden como parte de los patrones de cultura disponibles (Halliday, 1982). Dichos patrones culturales de significado y las configuraciones del contexto de situación son revitalizados cada vez que las necesidades de los grupos o redes sociales los ponen en juego (Latour, 2005). En el caso específico del contexto escolar, desde la perspectiva pedagógica, los significados se recrean en las aulas como organización de las 
relaciones sociales, las interacciones y las prácticas (Kress, 2010).

Una vez reconocida esta complejidad de los eventos semióticos -la simultaneidad de las metafunciones y la naturaleza contextual de los significados- redefiniremos las prácticas de aprendizaje y de enseñanza o mediación en el aula como prácticas semióticas (Kress, 2010). La alfabetización semiótica o multimodal plantea que los estudiantes aprenden a partir de textos de carácter multimodal, por esto, requieren apropiarse de dos elementos. Primero, de las formas gramaticales de los recursos semióticos utilizados para representar el conocimiento, con las particularidades de cada disciplina, en nuestro caso: geografía e historia, y física y biología. Segundo, necesitan apropiarse de la manera particular en que los distintos recursos son coutilizados para la semiosis en ese campo de conocimiento para poder acceder a ellos (Unsworth, 2006). Para estos aprendizajes se necesita la mediación del profesor. Tanto el aprendizaje como la mediación serían entonces prácticas semióticas.

El enfoque de la semiótica social tiene puntos importantes de encuentro con el enfoque sociohistórico de Vygotsky (Hasan, 2002) y su comprensión del ser humano social y cultural (Wells, 2001). Para Vygotsky (1995), las tecnologías de la comunicación -escritura, símbolos matemáticos, dibujo, etc.- son herramientas que corresponden a una representación externa de las formas de pensar el mundo en una cultura. En este sentido, la alfabetización semiótica es de importancia central en la escuela, puesto que en este contexto sociocultural el aprendiz amplía de manera importante su conocimiento respecto de las formas de representación de las diversas comunidades y culturas -que median entre su cultura y su mente semiótica-, y así amplía su manera de pensar el mundo (Manghi, 2011). Desde la perspectiva semiótica vigotskiana, los materiales para la enseñanza funcionan como instrumentos psicológicos concebidos implícitamente como mediadores representacionales en la zona de desarrollo próximo (Álvarez y Del Río, 2003).

\section{SIGNIFICADOS VISUALES E IMÁGENES BAJO ANÁLISIS}

Las imágenes están presentes cotidianamente en el aula. Por ejemplo, cuando el profesor habla frente al curso con un manual escolar en la mano, mostrando una página con una fotografía. La perspectiva multimodal nos indica que los significados se construyen a través de la interacción de los distintos medios y modos semióticos que convergen en cada evento comunicativo (Kress y Van Leeuwen, 2001). En esa página que el profesor muestra a los estudiantes hay un solo texto construido con el aporte de dos recursos: la lengua escrita y una imagen fotográfica, cada uno de ellos aporta significado. La construcción de significados de esta situación ocurre en la interacción cara a cara, y, por tanto, el significado completo solo se obtiene si se interpreta el ensamblaje semiótico de manera situada (Kress, 2010): la foto, la escritura, el habla y los gestos del profesor en esa situación particular. Reconocer que los significados se construyen de manera multimodal ofrece otra forma de comprender la semiosis que ocurre en el aula.

Los significados en el material impreso potencialmente pueden ofrecer un sentido intencionado por sus autores, los cuales en la interacción en el aula se dinamizan con el habla y los gestos que el profesor hace sobre la imagen estática (Manghi y Córdova, 2011), en interacción con los aportes que expresan sus estudiantes. Así, cada recurso aporta al significado global desde su epistemología semiótica o potencialidad para significar (Kress y Bezemer, 2009). Si aceptamos estos supuestos multimodales surgen entonces dos desafíos metodológicos: ¿Cómo explicar el significado que aportan las imágenes a este significado global complejo? ¿Cómo explicar la interrelación entre los distintos modos que construyen el evento comunicativo en la interacción cara a cara en el aula?

Para responder al primer desafío: ¿Cómo explicar el significado que aportan las imágenes a este significado global complejo? Kress y Van Leeuwen 
proponen una gramática del diseño visual (1996), basada en las metafunciones ya mencionadas. Esta gramática busca sistematizar herramientas para el análisis visual desde la mirada de la semiótica social. Las categorías de análisis presentan una base gramatical, en este caso, con evidencia de los distintos elementos presentes en la imagen; y se organizan redefiniendo visualmente las dos metafunciones centrales: la representacional y la interpersonal.

La primera metafunción, la ideacional (Halliday, 1982), corresponde a la representación y se basa en que cualquier sistema semiótico ofrece una teoría de la experiencia humana y para esto pone a disposición de quienes crean significado recursos para representar quién hace qué, a quién, cuándo, dónde, por qué y cómo (Eggins y Martin, 2003; Gutiérrez, 2011). En el caso de los materiales para la enseñanza, el significado ideacional, o significado representacional, como lo denominan Lemke (1998) y Kress y Van Leeuwen (2001), se asocia con la representación visual de los conocimientos que se espera aprendan los estudiantes. Dichos conocimientos corresponderían tanto al currículo oficial -los contenidos declarados en los documentos oficiales- como a los conocimientos del currículo oculto -entre los que se destacan las formas valoradas de expresar e interpretar en la disciplina, mediante el uso de algunos recursos semióticos y su interacción (Manghi, Badillo y Villacura, 2014)-.

En cuanto a los recursos visuales, como fotos e imágenes, la gramática visual propone que las imágenes pueden tener estructuras que nos permiten representar a los participantes de manera narrativa (procesos visuales de tipo material y conductual, es decir, que actúan y transforman la realidad que los rodea) y de manera conceptual (participantes en procesos visuales de identificación, es decir, participantes que no están en acción sino que son o muestran algún rasgo) (Altamirano, Godoy, Manghi y Soto, 2014). Mientras que entre las imágenes conceptuales los autores reconocen los siguientes tipos de relaciones: 1) clasificatoria: representa tipos de cosas o personas, miembros de una categoría; 2) analítica: representa ya sea una relación partes/todos, o de atributos de un todo; y 3) simbólica: representa participantes que son importantes por el significado que connotan.

Respecto a la segunda metafunción interpersonal, esta corresponde a la forma cómo se representa la comunicación con otros, los significados enactúan las relaciones sociales y personales con las otras personas del entorno con las cuales se interactúa. A partir del uso de diversos recursos semióticos se intercambian acciones comunicativas como: afirmaciones, preguntas, órdenes, expresando cómo valoramos a las personas y sus actos, cuán seguros nos sentimos de lo que comunicamos, o posicionándonos afectivamente respecto a lo que sentimos, etc. (Kress y Van Leeuwen, 1996).

En cuanto a la representación visual de la metafunción interpersonal, según la gramática del diseño visual, esta se realiza a partir de las interpretaciones sociales de los significados, y se representa a través de cinco formas visuales de establecer las relaciones: 1) contacto: relación entre el personaje representado y quien interpreta la imagen; 2) distancia social: cuán próxima o distante se establece la relación interpersonal; 3) perspectiva: cómo representamos las relaciones de poder de manera visual; 4) modalización: grado de veracidad de la imagen y a quién es atribuida la responsabilidad de la representación (Altamirano, Godoy, Manghi y Soto, 2014). Esta herramienta teórica y metodológica ha sido utilizada en los estudios sobre imágenes en textos escolares de Oteiza (2009), Pereira y González (2011); Altamirano, Godoy, Manghi y Soto (2014), y Farías y Araya (2014).

En relación al segundo desafío, ¿cómo explicar la interrelación entre los distintos modos que construyen el evento comunicativo en la interacción cara a cara en el aula?, lo que antes se consideraba extralingüístico, o un residuo en el texto, como las imágenes, fotos, fórmulas, gestos, entre otros, desde la perspectiva multimodal puede poseer el mismo estatus que el recurso lingüístico o en ocasiones uno mayor (Kress y Van Leeuwen, 2001) cuando confluyen en un mismo evento comunicativo. En 
este sentido, Barthes (1986) exploró la complejidad semiótica para la publicidad, desde sus conceptos de denotación y connotación. Describió imágenes dibujadas y fotografías, donde la mayor diferencia entre estas se da en la connotación. Barthes (1986) señala que el dibujo no reproduce todo, implica una selección por parte del creador; mientras que con la fotografía, este puede elegir el tema, el marco y el ángulo, pero no puede intervenir en el interior del objeto. En este sentido, la denotación del dibujo es menos pura que la denotación fotográfica, por lo que el dibujo es en sí connotación, mientras que para este autor la fotografía -si bien también es una selección de lo que se quiere mostrar- destaca por ser la evidencia de algo que pasó (la realidad de haber estado allí donde eso ocurrió).

Royce (2007) propone el concepto de intersemiosis para analizar cómo los modos lingüísticos e imagen se complementan semánticamente para producir un solo fenómeno textual. Ambos recursos realizan un trabajo semiótico conjunto para producir un texto multimodal coherente, en el cual cada recurso aporta al significado según su potencial epistemológico. Este potencial se ha moldeado culturalmente (Kress y Bezemer, 2009). Las relaciones intersemióticas o intermodales surgen de la interacción de varios recursos semióticos coutilizados para construir significado (Jewitt, 2009).

Por consiguiente, y para el caso específico de uso en aula de las imágenes que son el foco de este artículo, se consideran aquí como materiales de enseñanza, es decir, como artefactos culturales mediadores de interacciones discursivas entre los diferentes sujetos: autores, científicos, divulgadores, profesores, alumnos, que construyen conocimiento acerca de las Ciencias Sociales y Ciencias Naturales en la escuela (Martins, 2006). Consideraremos que el material visual para la enseñanza más que funcionar como un intermediario que reproduce cultura como parte de un dispositivo estático (Bernstein, 2000), este sería enactuado en cada instancia en que las imágenes son utilizadas por profesores y aprendices, transformando dinámicamente la situación de aprendizaje según las condiciones de su contexto y de los actores participantes en esta red (Latour, 2005). Este desafío metodológico guía el presente artículo.

\section{METODOLOGÍA}

Con el fin de explorar respuestas respecto a cómo explicar el significado que aportan las imágenes al significado global y complejo en la interacción profesor/aprendiz, y cómo explicar la interrelación entre los distintos modos que construyen el evento comunicativo, se presentan las herramientas teórico-metodológicas empleadas en esta investigación. La investigación corresponde a un estudio de caso con foco en los desafíos metodológicos y muestra la sistematización de un procedimiento para el análisis multimodal de las imágenes empleadas en el aula escolar en las áreas de Ciencias Sociales y Ciencias Naturales en una escuela pública chilena. El corpus es de naturaleza audiovisual y está conformado por las sesiones de clases videograbadas en Ciencias Naturales y Ciencias Sociales de tres cursos de una escuela pública chilena. En cada una de ellas se grabó una unidad didáctica completa (Tabla 1).

Tabla 1. Unidades curriculares grabadas

\begin{tabular}{llll}
\hline \multicolumn{1}{c}{ Unidad curricular } & \multicolumn{1}{c}{ Tercero básico } & \multicolumn{1}{c}{ Sexto básico } & \multicolumn{1}{c}{ Primero medio } \\
\hline Ciencias Naturales & Luz y sonido & Transferencia de energía & Fotosíntesis \\
Ciencias Sociales & Representaciones de la Tierra & Desastres naturales & Segunda Guerra Mundial \\
\hline
\end{tabular}

Fuente: elaboración propia. 
Para explorar el rol de las imágenes en el aula, a continuación se describen los conceptos teórico-metodológicos usados para el análisis multimodal del discurso en dos niveles:

1. Nivel macro, o satelital, que muestra el panorama comunicativo (Kress 2010).

- Para dar cuenta del carácter situado de la semiosis, se segmentaron las clases en actividades típicas de aula (de aquí en adelante ATA) las que para Lemke (1990) corresponden a secuencias de intercambios e intervenciones que presentan un objetivo o meta y un accionar conocido por los involucrados en el aula (Sánchez, García y Rosales, 2010), como activación de conocimientos previos, explicaciones, lecturas compartidas, entre otras.

- Luego se identificaron las imágenes tanto estáticas como dinámicas usadas por los profesores en el contexto de las ATA y de la unidad pedagógica trabajada.

2. Nivel micro, o del análisis semiótico, primero de imagen y luego de interacción cara a cara en el aula, o nivel pedagógico.

- Las imágenes se describieron en cuanto a los recursos empleados para la semiosis: el soporte material o medio (cara a cara, impreso o tecnológico) y en cuanto a los modos que se combinaron en ellas (escritura, fotografías, etc.); estos se clasificaron en imágenes estáticas (como fotos o dibujos) y dinámicas (como video).

- Se analizaron los significados construidos en la imagen utilizando las categorías ya descritas de la gramática del diseño visual de Kress y Van Leeuwen (1996), focalizando en las metafunciones ideacional e interpersonal.

- A continuación, nos devolvimos al video a analizar el contexto de la actividad e identificar los recursos (medios y modos) mediante los que el profesor construyó los significados usando la imagen para enseñar.
- Por último, y de manera general a partir de las metafunciones, se describen los significados construidos por el profesor en la interacción cara a cara al usar la imagen como material de enseñanza.

En "Resultados" se selecciona un ejemplo por cada curso y clase observados, con el propósito de mostrar una variedad de imágenes en distintas actividades de aula.

\section{RESULTADOS: SIGNIFICADOS VISUALES, IMÁGENES EN LA INTERACCIÓN EN EL AULA}

A continuación se presentan dos tablas (2 y 3) por asignatura que sintetizan los rasgos de las imágenes seleccionadas, contextualizando su uso en la actividad de aula en la que el profesor las emplea para resignificar el currículo. La Tabla 2 sintetiza algunos rasgos semióticos y pedagógicos del uso de las imágenes en los tres cursos de Ciencias Sociales. Se detallan, por curso, las características de cada uno en relación al potencial de significado visual y al potencial semiótico en la interacción de aula modificado con la mediación del profesor en la interacción cara a cara.

En la asignatura de Ciencias Sociales, en tercero básico se encontró el uso de imágenes estáticas como el mapa político para la unidad curricular "Representaciones de la Tierra", en una actividad de exposición conceptual por parte del profesor. Este medio impreso combina colores, escritura y distintos tipos de simbología, junto con las convenciones propias de este modelo de representación o mapa. En cuanto a la metafunción ideacional, el mapa político correspondió a una imagen conceptual analítica: el concepto representado era Chile (todo) y sus regiones (partes). En relación a la metafunción interpersonal, la imagen ofrece información con una distancia social media que permitió ver el todo y las partes con claridad, con una perspectiva frontal. Fue interesante la modalización, que correspondió a una representación científica, lo que implicaba que esta imagen requería el 
conocimiento de una serie de convenciones propias de las Ciencias Sociales para poder interpretar la información que esta comunicaba, y desarrollar la habilidad de interpretar representaciones espaciales a escala.

El potencial visual del mapa se dinamizó en la interacción cara a cara del profesor con sus estudiantes. Por una parte, el docente recurrió a esta imagen para evidenciar una forma en que la comunidad científica de la geografía ha acordado para representar la Tierra. El aporte linguistico del profesor fue extendido por el significado visual de esta representación científica, ya que agregaba información que en ningún momento fue representada mediante la lengua oral: límites del territorio, cercanía de las regiones, "dónde es mar", "dónde es cordillera", etc., no porque el profesor no tuviera la intención de decirla, sino porque se representaba de mejor manera a través de la imagen. Por otra parte, cuando el docente se acercaba a cada alumno para mostrarle las particularidades del mapa, lo hacía aprovechando el potencial del soporte impreso a dos caras: mostrando las diferencias en simbología y representación entre un mapa físico (una cara) y uno político (cara anversa). Este tipo de actividad les permitió aprender los elementos propios de los recursos de la cartografía, como ciencia auxiliar de la geografía.

En el caso del sexto básico, se utilizó el texto o manual escolar en una actividad de anticipación de la clase siguiente, para la unidad curricular de geografía: "Desastres naturales". La página en cuestión incluyó escritura, color y fotografías alusivas al tema. Desde lo ideacional, las fotografías eran de tipo clasificatorio, ya que mostraban ejemplos de distintos tipos de desastres naturales. Desde la metafunción interpersonal, las imágenes entregaban información, desde una distancia social lejana que permitía ver el panorama general, desde una perspectiva frontal y a través de una modalidad naturalista.

La profesora recurrió al potencial de la imagen para trabajar la causalidad. Ella les mostraba a los alumnos las imágenes y las categorizaba lingüísticamente como efectos de los desastres naturales. Al trabajar con este concepto causal, mediante el habla agregaba su posición respecto los desastres, asociándolos a las consecuencias en las personas, en la vida humana, utilizando adjetivos como cruel para calificar los efectos. De esta manera, la intersemiosis permitió que el estudiante categorizara los desastres naturales construyendo una tipología

Tabla 2. Síntesis rasgos semióticos de las imágenes en Ciencias Sociales

\section{EJEMPLOS IMÁGENES CIENCIAS SOCIALES}

Unidad pedagógica

Contexto actividad (ATA)

Tipo de medio

Tipo de imagen

Combinación de modos visuales en la interacción cara a cara

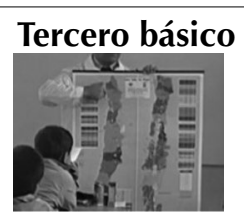

Representaciones de la Tierra

Conceptualización

Interacción cara cara y medio impreso: mapa.

\section{Estática}

Gestos, prosodia, habla proxemia; simbología, colores, escritura, convenciones del mapa.

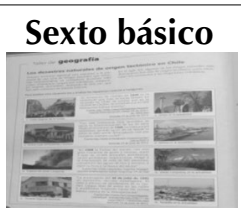

Desastres naturales Anticipación actividad Interacción cara a cara y medio impreso: texto o manual escolar.

Estática

Gestos, prosodia, habla; escritura, colores, tamaños, fotografías.

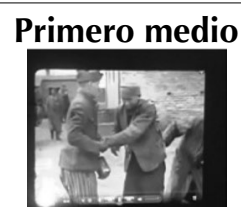

Segunda Guerra Mundial Explicación

Tecnológico: video documental, posterior interacción cara a cara.

Dinámica

Prosodia, gestos, habla; escritura, fotografías b/n y dibujos esquemáticos, narración en off.

Fuente: elaboración propia. 
lingüística, la cual a su vez correspondía a una versión visual que mostraba ejemplares de cada categoría.

Por su parte, para el primero medio, el profesor usó imágenes dinámicas para una explicación del tema curricular de historia "Segunda Guerra Mundial". El medio tecnológico video consistía en una narración para representar las consecuencias de los campos de concentración. En cuanto a la metafunción interpersonal, las imágenes del documental en ocasiones entregaban información y en algunos segmentos los personajes miraban directamente a la cámara, demandando información de la audiencia. Las personas y lugares se mostraban con una distancia social media y, en momentos, íntima, lo que permitió captar los detalles del rostro y su expresión. Algunas de las imágenes se presentaban desde una perspectiva vertical, ubicando los cuerpos de los prisioneros más abajo que el observador. La modalización era naturalista; al representar mediante registros reales tales sucesos, funcionando como evidencia de lo ocurrido, además el video era en blanco y negro lo que ayudó a ambientar el momento histórico.
El profesor presentó el video y medió su contenido una vez terminado, agregando antecedentes y causas del exterminio y preguntando a los aprendices sobre los estados emocionales que el video había generado en ellos. Con estas preguntas dio opciones para tomar postura frente a lo representado en el video. El docente asumió una posición frente a los hechos, calificándolos de lamentables y los relacionó con la violación a los derechos humanos en Chile. La combinación entre el video y la mediación lingüística del profesor permitió resignificar hechos históricos. Las imágenes aportaron significados diferentes a la lengua, contextualizando cómo era esa época, sus vestimentas, utensilios, tecnologías, etc., mientras que lingüísticamente el profesor modeló una posición frente a los acontecimientos históricos.

Estos tres ejemplos dan cuenta de las particularidades de los contenidos curriculares de historia, geografía y Ciencias Sociales, y su resignificación en el aula. A continuación usaremos las mismas categorías de análisis para revisar los ejemplos de Ciencias Naturales (Tabla 3).

Tabla 3. Síntesis rasgos semióticos de imágenes en Ciencias Naturales

\begin{tabular}{llll}
\hline & \multicolumn{1}{c}{ Tercero básico } & Sexto básico \\
EJEMPLOS IMÁGENES \\
CIENCIAS NATURALES
\end{tabular}

Fuente: elaboración propia. 
En cuanto a las clases de Ciencias Naturales y el curso de tercero básico, la imagen seleccionada era dinámica, a través de un video. El profesor lo seleccionó para iniciar la activación de conocimiento previo de la unidad curricular "Luz y sonido". Este medio tecnológico, en este caso, mostraba siluetas a contraluz, como un teatro de sombras.

En cuanto al potencial semiótico del video, este correspondió a una narración, ya que fue posible que quien interpretara reconociera participantes representados y vinculados entre sí a través de acciones. La narración planteaba una historia de amor, que no se relacionaba directamente con el contenido curricular, sino más bien utilizó el tema de aprendizaje como modo semiótico. Las relaciones interpersonales se asociaron con la entrega de información, a una distancia social media, desde una perspectiva frontal que indicaba igualdad de poder con quien interpretaba, y cuyas siluetas se acercaban a una representación naturalística del ser humano. Es decir, el profesor eligió una historia que interpersonalmente resultaría conocida y fácil de interpretar por los estudiantes.

En cuanto a su potencial semiótico, este recurso se modificó una vez que era mediado por el profesor. Aquí, luego de que los aprendices vieron el breve video, el docente dio inicio a una lluvia de ideas sobre lo visto, escribiendo en el pizarrón las que aportaban los niños. En este momento, los estudiantes destacaron tanto los episodios de la narración como los modos semióticos mediante los que las construyeron. El docente orientó sus respuestas para destacar los conceptos de luz, sombra y sonido, así como los juicios positivos sobre la forma de comunicar la historia y la narración misma, con conceptos como creatividad y amor, asumiendo una actitud frente al material para la enseñanza elegido. El profesor, al seleccionar estas imágenes y mediar en el video, corroboró que los niños habían actuado como interpretadores de una narración visual, en la cual no intervino el lenguaje.

En sexto básico la profesora desarrolló el tema "Transferencia de energía"; utilizó la interacción cara a cara junto con el medio impreso: texto o manual escolar y además el pizarrón para desarrollar una actividad de explicación. Las imágenes en ambos medios impresos eran estáticas y correspondieron a: una fotografía en el texto escolar y un dibujo esquemático en el pizarrón, y se combinaron con escritura, para etiquetar mediante una flecha o línea distintos elementos representados.

En cuanto al potencial para significar de las imágenes en texto escolar y en pizarrón, ambas construyeron el concepto de transferencia de energía de manera conceptual y analítica a partir de una imagen y sus componentes (planta: raíz, tallo, hojas, frutas). Interpersonalmente, fotografía y dibujo ofrecieron información, desde una distancia media que permitió ver las partes y el todo, una perspectiva frontal y una modalidad naturalística pero científica, ya que había convenciones científicas para interpretar ambas imágenes.

Cuando la docente medió el significado de las imágenes en la interacción con sus estudiantes, primero dibujó cada parte de la planta y la etiquetó lingüísticamente; luego leía un párrafo del texto escolar y mostraba la fotografía del libro. El dibujo en el pizarrón le permitió focalizar en cada parte, agregando detalles a elementos específicos mediante la oralidad, los cuales además representaba visualmente en el pizarrón. Es decir, construyó la representación conceptual analítica para sus estudiantes a través de ambas imágenes en interacción con la lengua oral. En cuanto a lo interpersonal, la profesora rescató el conocimiento de los niños, valorando positivamente sus intervenciones, es decir, se coconstruyó el conocimiento sobre transferencia de energía incorporando elementos de la vida cotidiana propuestos por los aprendices.

Por último, la profesora de primero medio usó un medio tecnológico: presentación computacional, más la interacción cara a cara para desarrollar una explicación en la unidad curricular "Fotosíntesis". La presentación mostraba una secuencia de imágenes estáticas, la mayoría de ellas correspondientes a dibujos esquemáticos que representaban conceptos analíticos, es decir, que mostraban plantas y las diferentes etapas y elementos de la fotosíntesis. 
Interpersonalmente, estas imágenes ofrecían información, desde una distancia media e íntima, ya que el recurso zoom es muy frecuente en biología, para representar de manera microscópica algún elemento particular del proceso. La perspectiva era frontal y, en el caso de las imágenes aumentadas o de zoom, era vertical; es decir, el científico observador en situación de poder frente al elemento natural representado. La modalización fue científica, ya que muchas de estas configuraciones correspondían a modelos de representación de la comunidad científica.

Cuando la profesora medió este material tecnológico en la interacción con sus estudiantes, los gestos y el habla cumplieron un rol determinante en cuanto a la metafunción ideacional. La imagen comenzó a funcionar como conceptual clasificatoria, el habla etiqueta lingüísticamente las categorías mostradas y los gestos sobre los modelos científicos colaboran en la identificación de los nombres técnicos científicos. Interpersonalmente, esta profesora se destacó por rescatar elementos propuestos por los aprendices, como la pacha mama o dios, aspectos que interrelaciona con la explicación científica sobre la vida natural. En este caso, la imagen correspondió a una representación de la comunidad científica, mientras que el recurso lingüístico permitió a la profesora moverse desde lo científico a lo cotidiano y viceversa.

\section{CONCLUSIONES}

La sistematización de herramientas de análisis multimodal utilizadas en este proyecto de investigación dan cuenta del significado visual en las imágenes desplegadas en el aula, mostrando que estas categorías son útiles metodológicamente para describir el potencial de significado y cómo este se modifica cuando es utilizado en la interacción cara a cara en el aula. La creación de significado visual también se considera como práctica social, y no solo como el uso de un elemento icónico (Dussel, 2011). En este sentido, permite representar la experiencia en el mundo, y también las relaciones interpersonales así como el posicionamiento respecto del interlocutor o del objeto representado. La selección y uso que hacen los profesores de las imágenes con fines pedagógicos son coherentes con la naturaleza de la disciplina. Desde la alfabetización de la geografía y la biología las representaciones son en sí mismas elementos técnicos para aprender a partir de ellas. Tanto los mapas como los dibujos esquemáticos son modelos de representación propios de estas comunidades y, por tanto, ofrecen múltiples convenciones visuales que hay que aprender a decodificar. Los profesores median en el desarrollo de este conocimiento.

En historia y geografía, las fotografías y videos funcionan como fuentes primarias o secundarias, es decir, evidencias de lo acontecido. En nuestros ejemplos son usadas para categorizar tipos de eventos (desastres naturales) así como representar consecuencias (exterminio judío). En ambas actividades los profesores promueven la toma de posición de los estudiantes frente a los acontecimientos, asumiendo ellos, en su rol de formadores, un compromiso actitudinal para con el tema.

Los materiales de enseñanza se presentan cada vez más multimodales, relacionando y potenciando la información visual estática de imágenes, letras, colores, tamaños con sonidos, imágenes dinámicas e hipervínculos. De esta forma, los profesores, quienes tradicionalmente han privilegiado las interacciones verbales para favorecer aprendizajes, se encuentran con una amplia variedad de recursos que pueden potenciar el aprendizaje, con la respectiva cautela de no confundir más multimodalidad sin sentido con mejor aprendizaje. Por eso es importante tomar conciencia de los potenciales para significar de cada recurso.

No obstante, el conocimiento multimodal es incipiente y no ha sido parte de la formación profesional aún; es posible confirmar que hasta ahora los profesores usan intuitivamente el potencial semiótico de cada recurso. Las elecciones de los docentes responden a sus propias creencias atribuidas a los significados de las imágenes. Sin embargo, en cuanto a la mediación pedagógica, nada de lo que 
el profesor hace es neutro y cada decisión sobre qué incorporar, hasta dónde hacerlo o no hacerlo, genera distintas oportunidades para crear significado para sus estudiantes; es decir, distinto potencial para el aprendizaje. Se proyecta continuar la próxima etapa del estudio con la incorporación de la voz de profesores y aprendices respecto de sus creencias en relación a la construcción de significados en las imágenes en contexto escolar.

\section{RECONOCIMIENTOS}

Investigación financiada por Fondecyt 1130684 (2013-2015). Agradecemos a la comunidad del colegio Dr. Oscar Marín Socias de Forestal Alto, Viña del Mar (Chile) por su participación en este estudio.

\section{REFERENCIAS}

Altamirano, P.; Godoy, G.; Manghi, D y Soto, G. (2014). Analizando los textos escolares de historia, geografía y Ciencias Sociales: la configuración multimodal de los pueblos originarios. Estudios Pedagógicos $X L(1), 263-280$.

Álvarez, A. y Del Río, P. (2003). Educación y desarrollo: la teoría de Vygotsky y la zona de desarrollo próximo. En: C. Coll, J. Palacios y A. Marchesi (comp.). Desarrollo psicológico y educación. Tomo Il Psicología de la Educación (pp. 119-131). Madrid: Alianza.

Barthes, R. (1986). La retórica de la imagen. En: Lo obvio y los obtuso (pp. 29-47). Barcelona: Paidós.

Bernstein, B. (2000). Pedagogy, symbolic control and identity. Londres: Rowan y Littlefield.

Dussel, I. (2011). Aprender y enseñar con nuevas tecnologías. VII Foro Latinoamericano de Educación. Buenos Aires: Fundación Santillana.

Eggins, S. y Martin, J. (2003). El contexto como género: una perspectiva lingüística funciona. Revista Signos, 36(54), 185-205.

Farías, M. y Araya, C. (2014). Alfabetización visual crítica y educación en lengua materna: estrategias metacognitivas en la comprensión lectora de textos multimodales. Colombian Applied Linguistics Journal, 16(1), 93-104.

Gutiérrez, R. (2011). Descripción sistémico-funcional y gramática multirregistro. Estudios Filológicos, 47, 59-82.

Halliday, M. (1982). El lenguaje como semiótica social. México, D.F.: Fondo de Cultura Económica.

Halliday, M. y Martin, J. (1997). Language, context and text: aspects of language in a social semiotic perspective. Oxford: Oxford University Press.

Hasan, R. (2002). Semiotic Mediation and Mental Development in Pluralistic Societies: Some Implications for Tomorrow's Schooling. En: G. Wells y G. Claxton (eds.). Learning for life in the 21st century: sociocultural perspectives on the future of education (pp. 112-26). Malden, MA: Blackwell Publishers.

Jewitt, C. (ed.) (2009). The Routledge Handbook of Multimodal Analysis. Londres: Routledge.

Kress, G. (2010). Multimodality: A social semiotic approach to contemporary communication. Londres: Routledge.

Kress, G. y Bezemer, J. (2009). Writing in a Multimodal World of Representation. Written Communication, 25(2), 166-195.

Kress, G. y Van Leeuwen, T. (1996). Reading images: the grammar of visual design. Londres: Routledge.

Kress, G. y Van Leeuwen, T. (2001). Multimodal Discourse. The Modes and Media of Contemporary Communication. Londres: Arnold.

Latour, B. (2005). Reensamblar lo social: una introducción a la teoría del actor-red. Buenos Aires: Manantial.

Lemke, J. (1990). Talking Science. Language, learning and values. Nueva Jersey: Ablex.

Lemke, J. (1998). Multiplying Meaning: Visual and Verbal Semiotics in Scientific Text. En: J. Martin y R. Veel (eds.). Reading Science: Critical and Functional Perspectives on Discourses of Science (pp. 87113). Londres: Routledge.

Llanos, C. y Otero, M. (2012). Un análisis de las características de los libros de matemática para la Enseñanza Secundaria con relación a la argumentación y las imágenes. Perspectiva Educacional, 51(2),119-148. 
Manghi, D. (2011). La perspectiva multimodal sobre la comunicación. Desafíos y aportes para la enseñanza en el aula. Diálogos Educativos, 11(22), 4-15.

Manghi, D. y Córdova, J. (2011). Definiciones y explicaciones multimodales en la enseñanza: potencial semiótico en la enseñanza de la biología en la escuela secundaria. Revista Logos, 21(2), 17-32.

Manghi, D.; Badillo, C. y Villacura, P. (2014). Alfabetización semiótica en clases de historia: estrategias de mediación desde un enfoque multimodal. Revista Perfiles Educativos, 36(146), 63-79.

Martins, I. (2006). Análisis de libros de texto en la perspectiva de los estudios del discurso: resultados de investigación e implicaciones para la práctica en aula. Recuperado el 6 de marzo de 2012 de: https://www.google.cl/webhp?sourceid=chrome-instant \&ion $=1 \&$ espv $=2 \&$ ie $=U T F-8 \# q=$ Martins $\% 2 \mathrm{C}+\mathrm{l} .+(2006) .+\mathrm{An} \% \mathrm{C} 3 \% \mathrm{~A} 1 \mathrm{lisis}+\mathrm{de}+$ libros+de+texto+en+la+perspectiva+de+los+estudios+del+discurso $\% 3 \mathrm{~A}+$ resultados+de+investigaci\%$\mathrm{C} 3 \% \mathrm{~B} 3 \mathrm{n}+\mathrm{e}+\mathrm{implicaciones}+$ para+la+pr\%C3\%A1 ctica+en+aula

Oteiza, T. (2009). Diálogo entre textos e imágenes: análisis multimodal de textos escolares desde una perspectiva intertextual. DELTA, 25, número especial 664-677.
Pereira, F. y González, G. (2011). Análisis descriptivo de textos escolares de lenguaje y comunicación. Lit. lingüíst., 24, 161-182.

Royce, T. (2007). Intersemiotic Complementarity: A Framework for Multimodal Discourse Analysis. En: T. Royce y W. Bowcher (eds.). New directions in the analysis of the multimodal discourse (pp. 63-109). Nueva Jersey: Lawrence Erlbaum Associates.

Sánchez, E.; García, P. y Rosales, J. (2010). La lectura en el aula. Qué se hace, qué se debe hacer y qué se puede hacer. Barcelona: Editorial Graó.

Van Leeuwen, T. y Humphrey S. (1996). On Learning to Look through a Geographer's Eyes. E.R. Hasan y G. Williams (eds.). Literacy in Society (pp. 29-49). Londres: Addison Wesley Longman.

Unsworth, L. (2006). Towards a Metalanguage for Multiliteracies Education: Describing the Meaning-Making Resources of Language-Image Interaction. English Teaching: Practice and Critique, 5(1), 55-76.

Van Leeuwen, T. (2005). Introducing Social Semiotics. Londres: Routledge.

Vigotsky, L. (1995). Pensamiento y lenguaje. Buenos Aires: Fausto.

Wells, G. (2001). Indagación dialógica. Hacia una teoría y una práctica socioculturales de la educación. Barcelona: Paidós 